\title{
Outcome of Fertility after Radical Conservative Surgery in Grade III-IV Endometriosis Lesions: A Retrospective Analysis
}

\author{
Jan Baekelandt ${ }^{1 \star}$, Annemarie Vandenbroucke ${ }^{1}$, Chris Aelvoet ${ }^{2}$, Sophie Pelckmans ${ }^{1}$ and Jan Bosteels ${ }^{1}$ \\ ${ }^{1}$ Department of Gynaecology and Obstetrics, AZ Imelda Hospital, Bonheiden, Belgium \\ ${ }^{2}$ Department of Surgery, AZ Imelda Hospital, Bonheiden, Belgium
}

\begin{abstract}
Purpose: Researching reproductive outcome after laparoscopic radical resection of grade III and IV endometrial lesions.

Methods and Materials: A retrospective analysis of 54 women was carried out. The patients underwent laparoscopic radical resection in the Gynecology Department of a secondary health care center between January 2009 and December 2013. Diagnostic investigation, with histological confirmation of moderate to severe endometriosis, preceded surgical intervention in a multidisciplinary setting. Thirty seven of the 54 patients had an active desire for pregnancy. The outcome measure was the number of pregnancies in the subgroup of 37 women with an active desire for pregnancy.

Results: Within the subgroup of 37 patients, 28 women became pregnant within the study period. Twelve patients became pregnant spontaneously and 16 had medically assisted pregnancies. Within the medically assisted group, 4 patients conceived after Intra-Uterine Insemination (IUI) and 12 after InVitro Fertilization (IVF). The pregnancy rate was $76 \%$, a result similar to findings of earlier studies.

Conclusion: The results of this retrospective analysis suggest that extensive laparoscopic surgery for moderate to severe endometriosis has a beneficial effect on fertility in both spontaneous and medically assisted pregnancies.
\end{abstract}

\section{Background}

Endometriosis is a prevalent condition defined by endometrial tissue outside the uterine cavity. The condition is estrogen-dependent and occurs mainly during the fertile period of women [1] .Prevalence is hard to quantify as definitive diagnosis requires laparoscopic investigation. Prevalence is estimated to be between 5 and $7 \%$ in al women [2]; in infertile populations prevalence may be up to $30 \%$ [3].

Some observational studies describing an elevated chance of pregnancy using GnRH without surgical approach exist, although the 2014 Cochrane review of these studies showed little evidence. Benefit of this approach remains controversial [12]. A recent, randomized trial confirmed that the use of GnRH agonists does not improve fertility in grade III to IV endometrial lesions [13].

The surgical approach of grade III to IV endometriosis lesions is often discussed in the current literature. The aims of the surgical approach are to remove all visible endometrial lesions using classical excision or ablation, restoring normal anatomy by opening adhesions. Discussion remains over whether the surgical approach is beneficial in relation to fertility in cases with grade III to IV endometrial lesions. Considering the invasive character of this approach, and the high risk of severe complications, such as transection of a ureter, pelvic abscesses or rectal damage, this discussion is extremely relevant $[14,15]$. Many studies researching the outcome on fertility after laparoscopic surgery for grade III to IV lesions are published, with often contradictory results. Adamson G, et al. [16] conducted an extensive meta-analysis on this topic in 1996, concluding that the surgical approach for grade III and IV lesions increases the chance of pregnancy by up to $44 \%$ in the laparoscopic approach, and up to $62 \%$ in laparotomy. Yet discussion persists over which surgical approach gives the maximal chance of pregnancy and minimal chance of complications. A recent prospective cohort study by Vercellini P. et al. [17] showed that, in the case of rectovaginal endometriosis, the surgical approach did not increase fertility in comparison to the control group with the conservative approach.

\section{Publication History:}

Received: January 21, 2016

Accepted: May 17, 2016

Published: May 19, 2016

\section{Keywords:}

Deep infiltrating endometriosis, Pregnancy rate, Infertility, Laparoscopy, Colorectal Endometriosis, Dysmenorrhea, IVF
The question remains whether the surgical approach to grade III and IV lesions improves the chance of pregnancy in patients with endometriosis. This question is central to our study, where the surgical approach for endometriosis is performed in a multidisciplinary setting.

\section{Material and Methods}

All patients who were operated on between January 2009 and December 2013 were included in this retrospective follow-up. They were treated with a radical conservative endometriosis removal. All patients were diagnosed preoperatively with grade III to IV endometriosis by clinical evaluation, transvaginal ultrasound, MRI and diagnostic laparoscopic surgery. This included rectovaginal plaques, deep infiltrativenodules, endometriomata, and grade IV sacro-uterine adhesions. Preoperatively all patients were treated with $\mathrm{GnRH}$-analogues for 3 months. The purpose of this treatment was to reduce the volume of the lesions as much as possible prior to surgery.

Postoperative histological survey confirmed the diagnosis of endometriosis in all patients. Histological criteria were the presence of glandular endometrial tissue or endometrial stroma in the biopsies. Symptoms were clinically monitored pre- and postoperatively per consultation in the Department of Gynecology at this center.

One patient was lost to follow-up and her data were not included in this survey. During post-operative contact, patients were questioned "Corresponding Author: Dr. Baekelandt Jan, Department of Gynaecology and Obstetrics, AZ Imelda Hospital, Bonheiden, Belgium; E-mail: jan.baekelandt@imelda.be

Citation: Baekelandt J, Vandenbroucke A, Aelvoet C, Pelckmans S, Bosteels J (2016) Outcome of Fertility after Radical Conservative Surgery in Grade III - IV Endometriosis Lesions: A Retrospective Analysis. Int J Gynecol Clin Pract 3: 119. doi: http://dx.doi.org/10.15344/2394-4986/2016/119

Copyright: (C) 2016 Baekelandt et al. This is an open-access article distributed under the terms of the Creative Commons Attribution License, which permits unrestricted use, distribution, and reproduction in any medium, provided the original author and source are credited. 
Citation: Baekelandt J, Vandenbroucke A, Aelvoet C, Pelckmans S, Bosteels J (2016) Outcome of Fertility after Radical Conservative Surgery in Grade III - IV Endometriosis Lesions: A Retrospective Analysis. Int J Gynecol Clin Pract 3: 119. doi: http://dx.doi.org/10.15344/2394-4986/2016/119

Page 2 of 4

about child wish, smoking behavior, spontaneous pregnancy, medically assisted pregnancies, sperm examination and other important non-medical parameters such as separation of partners.

Our primary endpoint postoperatively was number of pregnancies, including both spontaneous and medically assisted pregnancies.

\section{Operative Procedure}

The patient was placed in the lithotomy position under general anaesthesia. A double-J stent was placed in each ureter and a Foley catheter was inserted into the bladder. All procedures were performed by $\mathrm{BJ}$ (first author) in a multidisciplinary setting where rectal resections were performed by AC (third author). A pneumoperitoneum was created by placing a Verress needle and insufflating 3 liters of $\mathrm{CO}_{2}$. Two $10 \mathrm{~mm}$ trocars were placed: one in the umbilicus and one in the right iliac fossa. Five $\mathrm{mm}$ trocars were placed suprapubically and in the left iliac fossa. All endometriotic lesions were excised using monopolar and bipolar instruments. All bladder endometriosis was excised using monopolar instruments; the bladder was sutured laparoscopically. For endometriomas a cystectomy was performed. Rectovaginal nodules were excised after rectal shaving using a monopolar hook electrode. When a rectal resection was indicated, a reanastomosis was performed using transanal stapling.

\section{Patients}

The number of women operated between January 2009 and December 2013 was 54.

Preoperative pain was scored in 4 grades of dysmenorrhea. The median score was 2 [0-4]. Postoperative pain was not scored systematically, and pre- versus postoperative pain could therefore not be compared.

Within the 54 patient group, there were 14 patients (26\%) for whom the indication for surgery was pain-reduction and not infertility. This subgroup was excluded. The remaining 40 patients (74\%) were operated due to subfertility and active child wish. Patients with conflicting fertility factors, such as active smoking behavior and obesity $(\mathrm{BMI}>30)$ [18], were also excluded. Two patients were excluded as their relationship ended shortly after surgery. One patient was lost to follow-up, and her data were excluded from this study. After these exclusions a subpopulation of 37 patients remained (69\%) and an overview of their results is presented in Table 1.

The median duration of preoperative sub fertility was 19,4 months (0-72). The WHO definition of 2009 defines infertility as an absence of pregnancy for at least 12 months [19], thus this population was classified as infertile. The median age at surgery was 31,5 years [ 23 38 , median BMI $23,4(17,7-31,1)$, median preoperative parity was 0 [0-1], and gravidity was 0 [0-3] Table 2 .

The anatomic characteristics of the population are more heterogeneous. Within the subgroup of 37 patients, there were 26 deep nodules (70\%), 10 vesical nodules (27\%), 7 accompanying extensive peritoneal lesions (19\%), and 12 accompanying endometriomata (32\%)

Two patients had an adnexectomy for extensive endometrial cysts (5\%), two patients had an unilateral Fallopian tube resection (5\%), and one patient had a bilateral Fallopian tube resection for bilateral hydrosalpinx (3\%). IVF was commenced immediately after surgery. In 11 patients, surgery was extended to the rectal wall (30\%). Lesions were removed either by shaving the rectal wall, or by rectal resection. Five patients underwent radical rectum resection (14\%) and shaving was performed in six patients (16\%). The decision to use either of these techniques was based upon invasion depth of the lesions in the rectal wall. In 7 patients surgical re-intervention was necessary due to persisting pelvic pain(19\%).These results are shown in Table 3.

\begin{tabular}{|l|c|}
\hline Initial population & $\mathrm{n}=54(100 \%)$ \\
\hline Antalgic indication & $\mathrm{n}=14(26 \%)$ \\
\hline Postoperative breakup & $\mathrm{n}=2(3 \%)$ \\
\hline Lost to follow-up & $\mathrm{n}=1(2 \%)$ \\
\hline BMI $>35$ & $\mathrm{n}=0 \quad(0 \%)$ \\
\hline Active smoking & $\mathrm{n}=0(0 \%)$ \\
\hline Included patients & $\mathrm{n}=37(69 \%)$ \\
\hline
\end{tabular}

Table1: Exclusion criteria.

\begin{tabular}{|l|l|}
\hline Characteristics & Median [range] \\
\hline Age & $31,5[23-38]$ \\
\hline Pre-operative gravidity & $0[0-3]$ \\
\hline Pre-operative parity & $0[0-1]$ \\
\hline Dysmenorrhea & $2[0-4]$ \\
\hline BMI & $23,4[17-7 ; 31-1]$ \\
\hline Subfertile period (months) & $19,4[0-72]$ \\
\hline
\end{tabular}

Table 2: Patientdemography.

\begin{tabular}{|l|l|}
\hline Characteristics & $\mathrm{n}=37(100 \%)$ \\
\hline Deep Nodule & $\mathrm{n}=26(70 \%)$ \\
\hline Vesicalnodule & $\mathrm{n}=10(27 \%)$ \\
\hline Peritoneallesions & $\mathrm{n}=7(19 \%)$ \\
\hline Endometriomata & $\mathrm{n}=12(32 \%)$ \\
\hline Adnexectomy & $\mathrm{n}=2(5 \%)$ \\
\hline Unilat. Fallopian resection & $\mathrm{n}=2(5 \%)$ \\
\hline Bilat.Fallopian resection & $\mathrm{n}=1(3 \%)$ \\
\hline Rectal resection & $\mathrm{n}=5(14 \%)$ \\
\hline Shaving of the rectum & $\mathrm{n}=6(16 \%)$ \\
\hline Table 3: Type of surgery. & \\
\hline
\end{tabular}

\section{Results}

In the subpopulation of 37 patients, 18 spontaneous pregnancies occurred in 12 women. Two women became pregnant three times, two women twice and seven women once. The median period to conception in this subpopulation was 6 months (1-32). Four pregnancies were conceived using Intra-Uterine Insemination after ovarian induction in 4 women. The time to conception was 6.5 months (3-15). Thirteen women in total tried IUI. Thirteen pregnancies were conceived after IVF in 12 women. In these pregnancies 2 women combined IVF with Intra-Cytoplasmic Sperm Injection (ICSI).

A total number of 17 women attempted fertility treatment using IVF. As 12 of them fell pregnant, the total success rate of postoperative IVF treatment was $71 \%$. 
Citation: Baekelandt J, Vandenbroucke A, Aelvoet C, Pelckmans S, Bosteels J (2016) Outcome of Fertility after Radical Conservative Surgery in Grade III - IV Endometriosis Lesions: A Retrospective Analysis. Int J Gynecol Clin Pract 3: 119. doi: http://dx.doi.org/10.15344/2394-4986/2016/119

Page 3 of 4

Combining all these results, 28 of 37 women became pregnant, bringing the postoperative pregnancy rate to $76 \%$. These results are presented in Table 4.

\begin{tabular}{|l|ll|}
\hline Total population & $\mathrm{n}=37$ Pregnancies \\
\hline Spontaneous pregnancy & $\mathrm{n}=12$ & 18 \\
\hline Non-spontaneous pregnancy & $\mathrm{n}=16$ & 17 \\
\hline IUI conception & $\mathrm{n}=4$ & 4 \\
\hline IUI no conception & $\mathrm{n}=9$ & 0 \\
\hline IVF conception & $\mathrm{n}=10$ & 11 \\
\hline IVF + ICSI conception & $\mathrm{n}=2$ & 2 \\
\hline IVF no conception & $\mathrm{n}=5$ & 0 \\
\hline Pregnancy Rate & $76 \%$ & \\
Table 4: Pregnancy rate after surgery. &
\end{tabular}

\section{Discussion}

A pregnancy rate of $76 \%$ confirms earlier results presented by Adamson $\mathrm{G}$ et al. (44\% pregnancy rate after laparoscopy and $62 \%$ after laparotomy). Daraï et al. found a pregnancy rate of $45,5 \%$ after laparoscopic resection or shaving of the rectal wall. In this study, a higher percentage of spontaneous pregnancies were reported (75\%) [20] . A recent large prospective cohort study showed a pregnancy rate of $51 \%$. This study researched the benefit of rectum resection in patients with grade III to IV lesions [21].

Our results show a pregnancy rate of $76 \%$, which is higher than the average percentages found in recent literature. A possible explanation for this difference is the relatively small population size in this study. As our study only included 37 patients, a form of selection bias may explain the higher results compared to those found in the literature.

Median time to conception was 6 months with a range of 1-32. This number is similar to the result of Darai et al., [21] who found a median time to conception of 8 months with a range of 3-13.

A striking conclusion in our study is the high success rate of postoperative IVF treatment. Bianchi P, et al. illustrated that radical resection of Deep infiltrative Endometriosis significantly improved IVF treatment success rates. In their prospective cohort analysis a pregnancy rate of $24 \%$ without and $41 \%$ with surgery was found [22]. In our study, the post-operative success rate of IVF treatment was remarkably higher, namely $71 \%$. A possible explanation for this finding is again the smaller number of patients included ( 37 patients in our study versus 179 patients in the study by Bianchi et al.) [22], as well as different characteristics of the selected populations. The study performed by Bianchi et al. mostly described women with DIE, while in this analysis we focused on grade III to IV lesions with rectovaginal involvement.

Considering the evaluation of post-operative pain, no standardized pain scoring system was used. Seven of $37(n=7,19 \%)$ patients needed surgical re-intervention due to persisting pelvic pain.

Analysis of results found in this study confirms that radical surgery improves fertility in grade III to IV endometrial lesions. Careful interpretation of these results however is recommended. The retrospective character of this study, variable time of follow-up, lack of a well-defined control population, and limited population size, make drawing conclusions difficult. Another downside of this analysis is that due to lack of data, only a pregnancy ratecould be determined, and not acumulative pregnancy rate, which would make analysis of the results more accurate. Further prospective, randomized studies with an adequate control arm are required in the future, not only focusing on pregnancies but also on complications, relapses and quality of life in order to make a complete interpretation of the effects of surgical intervention. Further research should be conducted to understand the physiological mechanisms of endometriosis and the concomitant effects on fertility. Results of such research will eventually lead to an approach other than surgical intervention or medical treatment with GnRH agonists [23].

Further challenges of surgical intervention for endometriosis are when to proceed with medically assisted pregnancy in the postoperative setting, and how long one should wait for spontaneous conception, to prevent starting premature and expensive IVF treatment. Alternatively, how long can one wait before starting IVF treatment so that time is not lost in worse prognostic categories. Adamson et al. published an interesting scoring system in 2010: the Endometriosis Fertility Index (EFI). This staged scoring system attempts to quantify post-operative success rate of spontaneous conception (0-10) using several factors, including extensiveness of endometrial lesions, post-operative Fallopian functionality and historical factors [24]. This tool was verified in 2013 as a moderate qualitative indicator [25]. This scoring system can aid in deciding when to attempt medically assisted pregnancy in the post-operative setting.

\section{Competing Interests}

The authors declare that they have no competing interests.

\section{References}

1. Jacobson TZ, Duffy JM, Barlow DH, Farquhar C, Koninckx PR et al. (2008) Laparoscopic surgery for subfertility associated with endometriosis. Cochrane Database Syst Rev.

2. Ozkan S, Murk W, Arici A (2008) Endometriosis and infertility: epidemiology and evidence-based treatments. Ann N Y Acad Sci 1127: 92-100.

3. Missmer SA, Hankinson SE, Spiegelman D, Barbieri RL, Marshall LM, et al. (2004) Incidence of laparoscopically confirmed endometriosis by demographic, anthropometric, and lifestyle factors. Am J Epidemiol 160: 784-796.

4. Davis CJ, McMillan L (2003) Pain in endometriosis: effectiveness of medical and surgical management. Curr Opin Obstet Gynecol 15: 507-512.

5. Bulun SE (2009) Endometriosis. N Engl J Med 360: 268-279.

6. [No authors listed] (1985) Revised American Fertility Society classification of endometriosis: 1985. Fertil Steril 43: 351-352.

7. Yap C, Furness S, Farquhar C (2004) Pre and post operative medical therapy for endometriosis surgery. Cochrane Database Syst Rev CD003678.

8. D'Hooghe TM, Debrock S, Hill JA, Meuleman C (2003) Endometriosis and subfertility: is the relationship resolved? Semin Reprod Med 21: 243-254.

9. Bulun SE (2009) Endometriosis. N Engl J Med 360: 268-279.

10. Gupta S, Goldberg JM, Aziz N, Goldberg E, Krajcir N, et al. (2008) Pathogenic mechanisms in endometriosis-associated infertility. Fertil Steril 90: 247-257.

11. Witz CA, Burns WN (2002) Endometriosis and infertility: is there a cause and effect relationship? Gynecol Obstet Invest 53 Suppl 1: 2-11.

12. Brown J, Farquhar C (2014) Endometriosis: an overview of Cochrane Reviews. Cochrane Database Syst Rev 3: CD009590. 
Citation: Baekelandt J, Vandenbroucke A, Aelvoet C, Pelckmans S, Bosteels J (2016) Outcome of Fertility after Radical Conservative Surgery in Grade III - IV Endometriosis Lesions: A Retrospective Analysis. Int J Gynecol Clin Pract 3: 119. doi: http://dx.doi.org/10.15344/2394-4986/2016/119

Page 4 of 4

13. Loverro G, Carriero C, Rossi AC, Putignano G, Nicolardi V, et al. (2008) A randomized study comparing triptorelin or expectant management following conservative laparoscopic surgery for symptomatic stage III and IV endometriosis. Eur J Obstet Gynecol Reprod Biol 136:194-198.

14. Ford J, English J, Miles WA, Giannopoulos T (2004) Pain, quality of life and complications following the radical resection of rectovaginal endometriosis. BJOG 111: 353-356.

15. Mohr C, Nezhat FR, Nezhat CH, Seidman DS, Nezhat CR (2005) Fertility considerations in laparoscopic treatment of infiltrative bowel endometriosis. See comment in PubMed Commons below JSLS 9: 16-24.

16. Adamson GD1, Pasta DJ (1994) Surgical treatment of endometriosisassociated infertility: meta-analysis compared with survival analysis. See comment in PubMed Commons below Am J Obstet Gynecol 171: 14881504.

17. Vercellini P, Pietropaolo G, De Giorgi O, Daguati R, Pasin R, et al (2006) Reproductive performance in infertile women with rectovaginal endometriosis: is surgery worthwhile? Am J Obstet Gynecol 195: 13031310.

18. Rittenberg V, Seshadri S, Sunkara SK, Sobaleva S, Oteng-Ntim E, et al (2011) Effect of body mass index on IVF treatment outcome: an updated systematic review and meta-analysis. Reprod Biomed Online 23: 421-439.

19. Zegers-Hochschild F, Adamson G, Muzon J, Ishihara O, Mansour R, et al. (2009) International Committee for Monitoring Assisted Reproductive Technology (ICMART) and the World Health Organization (WHO) revised glossary of ART terminology. Fertil Steril 92: 1520-1524.

20. Daraï E, Marpeau O, Thomassin I, Dubernard G, Barranger E, et al (2005) Fertility after laparoscopic colorectal resection for endometriosis: preliminary results. Fertil Steril 84: 945-950

21. Meuleman C, Tomassetti C, Wolthuis A, Van Cleynenbreugel B, Laenen A, et al. (2014) Clinical outcome after radical excision of moderate-severe endometriosis with or without bowel resection and reanastomosis: a prospective cohort study. Ann Surg 259: 522-531.

22. Bianchi PH, Pereira RM, Zanatta A, Alegretti JR, Motta EL, et al. (2009) Extensive Excision of Infiltrative Endometriosis before In Vitro Fertilization Significantly Improves Pregnancy Rates. J Minim Invasive Gynecol 16 174-180.

23. D'Hooghe TM, Debrock S, Meuleman C, Hill JA, Mwenda JM (2003) Future directions in endometriosis research. Obstet Gynecol Clin North Am 30 221-244.

24. Adamson GD, Pasta DJ (2010) Endometriosis fertility index: the new, validated endometriosis staging system. Fertil Steril 94: 1609-1615.

25. Tomassetti C, Geysenbergh B, Meuleman C, Timmerman D, Fieuws S et al. (2013) External validation of the endometriosis fertility index (EFI) staging system for predicting non-ART pregnancy after endometriosis surgery. Hum Reprod 28: 1280-1288. 